\title{
Study of addition of fentanyl to bupivacaine in subarachnoid block administered for cemented bipolar prosthesis in geriatric patients population
}

\author{
Sarita Gohiya ${ }^{1, *}$, Vineet Kumar Gohiya ${ }^{2}$, Nisha Singh $^{3}$ \\ ${ }^{\mathbf{1}}$ Associate Professor, ${ }^{2}$ Professor and Head, ${ }^{3}$ Demonstrator, ${ }^{1}$ Dept. of Anaesthesiology, ${ }^{2}$ Dept. of Anatomy, ${ }^{3}$ Dept. of Community \\ Medicine, Government Medical College, Khandwa, Madhya Pradesh, India \\ *Corresponding Author: Sarita Gohiya \\ Email: drsgohiya@gmail.com
}

Received: $14^{\text {th }}$ May, 2018

Accepted: $14^{\text {th }}$ July, 2018

\begin{abstract}
Introduction: The most restricting component of regional anaesthesia in geriatric patients is hypotension inspite of several advantages. The present study aimed to reduce hypotensive effect of local anaesthetics by reducing their dose and by adding fentanyl.

Materials and Methods: We selected 120 elderly patients ( $\geq 65$ years) scheduled for cemented bipolar prosthesis under spinal anaesthesia. They were randomized into two groups (Group - I: $\mathrm{n}=60$, Group - II: $\mathrm{n}=60$ ). Group I patients received $2.5 \mathrm{ml}$ of $0.5 \%$ hyperbaric Bupivacaine and Group II patients received $2 \mathrm{ml}$ of $0.5 \%$ hyperbaric Bupivacaine plus $25 \mu \mathrm{gm}$ fentanyl. Duration of surgery, hemodynamic variables, adverse effect, need for analgesic supplementation were recorded.

Result: Hypotension was more frequent in Group-I than Group-II (83.3\% versus $8.33 \%$ ). Bradycardia is more in Group-I than in Group-II (66.67\% versus 5\%). Need of I. V. Fentanyl for alleviation of discomfort was same in both groups.

Conclusion: Addition of intrathecal fentanyl provides better hemodynamic stability without compromising quality of anaesthesia.
\end{abstract}

Keywords: Analgesia, Bupivacaine, Fentanyl, Geriatric patients, Intrathecal, Spinal anaesthesia.

\section{Introduction}

According to population survey done in 2011 there are approximately 104 million elderly persons [aged 60 years or above] in India. In 1961 elderly population was $5.6 \%$ which was increased to $8.6 \%$ in 2011 . As geriatric population get increased operative work on them is also increased. Older age is a significant risk factor for poor outcome after orthopaedic surgery. Geriatric patients presenting for orthopaedic surgery often have multiple co-morbid conditions that must be considered in the perioperative anaesthetic plan. For many orthopaedic procedures, regional anaesthesia may reduce perioperative complications compared with general anaesthesia and provide superior post operative analgesia. ${ }^{1}$ Regional anaesthesia may provide preemptive analgesia, and some evidence exists that regional analgesia may block the progression of severe acute post-operative pain in to a chronic pain syndrome. $^{2}$ In addition to improved pain control, functional outcome in the form of physical therapy milestones may benefit from both regional anaesthesia and analgesia. ${ }^{3}$ The present study aimed to reduce hypotensive effect of local anaesthetics by reducing their dose and by adding fentanyl in geriatric patients posted for cemented bipolar prosthesis under spinal anaesthesia.

\section{Materials and Methods}

This prospective, randomized double blind study was approved by Institutional Ethical Committee (IEC). This study was carried out on 120 patients of ASA grade I and II aged $\geq 65$ yrs, scheduled for cemented bipolar prosthesis, under spinal anaesthesia were elected after taking informed consent. Patients having history of allergy to any of the study medication and contraindication to spinal anaesthesia were excluded.

In this study, two groups $(n=60)$ were investigated: Group I received $2.5 \mathrm{ml}$ of hyperbaric Bupivacaine $0.5 \%$ and Group II received $2 \mathrm{ml} 0.5 \%$ hyperbaric bupivacaine plus $25 \mu \mathrm{gm}$ fentanyl. The anaesthetic solution was prepared according to a random number table by means of a computer generated randomized list by an anaesthetist not otherwise involved in the study. The anaesthetist performing the block was blinded to the treatment group. All observations were carried out by a single investigator who was also blinded to the treatment group.

All patients were fasted for $8 \mathrm{hrs}$. In the preoperative room glycopyrrolate $0.2 \mathrm{mg}$ was administered intramuscularly as premedication. A good i.v. access was secured and preloading done with Ringer lactate $8 \mathrm{ml} / \mathrm{kg}$. In the operative room, all monitors were attached and base line parameters were observed and recorded which included heart rate, mean arterial pressure, electrocardiogram, respiratory rate and pulse oximetry. Spinal anaesthesia was performed in the sitting position using 25 gauze Quincke's spinal needle at $\mathrm{L}_{3}-\mathrm{L} 4$ interspace. Thereafter, Group I received $2.5 \mathrm{ml}$ hyperbaric Bupivacaine $0.5 \%$ and Group II received $2 \mathrm{ml}$ hyperbaric Bupivacaine $0.5 \%$ plus $25 \mu \mathrm{gm}$ fentanyl in spinal anaesthesia. Patient position changed from sitting to supine immediately after injecting the drug. Operation theatre table kept 
horizontal throughout the procedure. Patient brings down to lateral decubitous position 20 minute after injecting the drug. After spinal anaesthesia, heart rate and mean arterial pressure recorded every 3 minutes for 30 minutes. After that heart rate and mean arterial pressure recorded every 5 minutes throughout the procedure. Levels of sensory block were checked by pin prick method with the 24 gauze needle every 5 minutes for initial 20 minutes after injecting the drug. Levels of motor block were checked by modified Bromage scale every 5 minutes for initial 20 minutes after injecting the drug. Modified Bromage scale: $0=$ free movement of lower limbs, $1=$ inability to raise the extended limbs, 2 = inability to flex knees, 3 = inability to move the ankles. In case of inadequate block, general anaesthesia was given.

The quality of anaesthesia was observed by following manner: 'very good' - the patient was satisfied; 'good' - the analgesia was complete though the patient was not comfortable due to the position of the leg and demanded iv medication; 'insufficient' - the analgesia was not complete and the patient required additional nerve blockage and analgesic; 'failure'analgesia was insufficient and general anaesthesia was administered. Duration of surgery was calculated from incision of skin to closure of skin.

Bradycardia [heart rate $<50$ beat per minute] and hypotension [mean arterial blood pressure $<20 \%$ of base line value] were documented and treated with intravenous fluid or iv ephedrine or atropine. Adverse effects like respiratory depression $\left[\mathrm{SpO}_{2}<90 \%\right]$, pruritus, nausea, vomiting, and shivering were recorded. Patient shifted to recovery room after completion of the procedure.

Unpaired student' $t$ ' test and chi- square test were used for analyzing the data. $\mathrm{p}$ value $<0.05$ were considered statistically significant.

\section{Results}

The demographic characteristics and ASA physical status of the two groups are shown in Table 1. Both the groups were comparable according to age, weight and ASA physical status. Datas are expressed as mean \pm SD.

Table 2 shows the number of patients having hypotension and Bradycardia in two groups. Number of patients requiring iv fentanyl during operation also depicted in table no. 2. Only $8.33 \%$ patients in group II required iv ephedrine for treatment of spinal induced hypotension in comparison to $83.3 \%$ patient in group I. Bradycardia is also more frequent in group I [66.67\%] in comparison to group II [5\%]. Number of patient's required iv fentanyl for alleviation of discomfort during surgery were same in both groups [p $>0.05]$. Duration of surgery was same in both groups [ $p>0.05]$.

Few adverse effects were observed [Table 3] in both groups. Incidence of shivering, nausea and vomiting was same. Incidence of pruritus was more in group II which was mild and subsides without treatment. There was no respiratory depression in any study group.

Table 1: Demographic Data [Mean \pm SD]

\begin{tabular}{|c|c|c|c|}
\hline S. No & Patient characteristics & Group I [n=60] & Group II [n=60] \\
\hline 1. & Age [years] & $70.82 \pm 4.36$ & $72.62 \pm 4.61$ \\
\hline 2. & Weight [kilogram] & $72.1 \pm 10.3$ & $68.9 \pm 9.21$ \\
\hline 3. & ASA physical status I/II & $40 / 20$ & $36 / 24$ \\
\hline 4. & Duration of surgery (Min) & $42.47 \pm 9.94$ & $43.67 \pm 10.55$ \\
\hline
\end{tabular}

Table 2: Hemodynamic parameters $[\mathrm{n}=60]$

\begin{tabular}{|l|c|c|c|c|c|c|}
\hline \multirow{2}{*}{ S. No. } & \multirow{2}{*}{ Effect } & \multicolumn{2}{|c|}{ Group I } & \multicolumn{2}{c|}{ Group II } & \multirow{2}{*}{ p value } \\
\cline { 3 - 7 } & & No. of Pt. & $\mathbf{\%}$ & No. of Pt. & \% & \\
\hline 1. & Hypotension & 50 & 83.3 & 05 & 8.33 & $<0.0001$ \\
\hline 2. & Bradycardia & 40 & 66.66 & 03 & 5 & $<0.0001$ \\
\hline 3. & $\begin{array}{c}\text { Analgesic } \\
\text { supplementation }\end{array}$ & 07 & 11.66 & 06 & 10 & 0.7690 \\
\hline
\end{tabular}

Table 3: Adverse effects [ $n=60]$

\begin{tabular}{|l|c|c|c|c|c|}
\hline \multirow{2}{*}{ S. No } & \multirow{2}{*}{ Adverse effect } & \multicolumn{2}{|c|}{ Group I } & \multicolumn{2}{c|}{ Group II } \\
\cline { 3 - 6 } & & No. of Pt. & \% & No. of Pt. & \% \\
\hline 1. & Shivering & 10 & 16.67 & 08 & 13.33 \\
\hline 2. & Pruritus & 00 & - & 06 & 10 \\
\hline 3. & Nausea & 02 & 3.33 & 03 & 5 \\
\hline 4. & Vomiting & 04 & 6.67 & 03 & 5 \\
\hline 5. & Respiration depression & 00 & - & 00 & - \\
\hline
\end{tabular}




\section{Discussion}

Regional anaesthesia has several advantages over general anaesthesia in orthopaedic procedures. Regional anaesthesia may reduce the incidence of major perioperative complications such as deep venous thrombosis, pulmonary embolism, blood loss, respiratory complications, and death. ${ }^{4-6}$ Hypotension is most limiting factor of spinal anaesthesia. Several studies are carried out for reducing the incidence of hypotension. ${ }^{6-11}$

This study has demonstrated that by reducing the dose of Bupivacaine and by adding the Fentanyl to Bupivacaine, we can avoid hypotension and Bradycardia without compromising the quality of anaesthesia. This is attributable to the fact that intrathecal opioids appear to produce analgesia by inhibition of synaptic transmission in nociceptive afferent pathways (A delta and $\mathrm{C}$ fibres) ${ }^{12}$ and yet, they don't inhibit conduction in sympathetic pathways or somatosensory evoked potentials. ${ }^{12,13}$

Various studies have been conducted on intrathecal Fentanyl with smaller doses of local anaesthetics. BenDavid et al found that low dose $(4 \mathrm{mg})$ isobaric Bupivacaine plus $20 \mu \mathrm{gm}$ Fentanyl, in comparison with a $10 \mathrm{mg}$ isobaric Bupivacaine, provide adequate spinal anaesthesia and less hypotension for surgical repair of hip fracture in the elderly. ${ }^{14}$ Similar to our study Leo $\mathrm{S}$ et al and Roofthooft $\mathrm{E}$ et al also found that incidence of hypotension was decreased on reducing the dose of $0.5 \%$ hyperbaric Bupivacaine. ${ }^{15,16}$

One another study, conducted by Van de Velde M et al, demonstrated that by addition of Sufentanyl to Bupivacaine, better hemodynamic stability and equally effective anaesthesia is achieved. ${ }^{17}$ Bogra $\mathrm{J}$ et al concluded that synergistic effect of Fentanyl able to reduce the dose of Bupivacaine and therefore its harmful effects. ${ }^{18}$

Side effects are same in both groups. Number of patients required analgesic supplementations are also same in both the groups. Intrathecal opoids cause pruritus which was mild and need no treatment. Some other researchers Liu et al, Vaghadia et al were also found pruritus of mild to moderate intensity. ${ }^{19,20}$ The incidence of respiratory depression in our study was nil in both the groups because Fentanyl is lipophilic opioid unable to reach to the $4^{\text {th }}$ ventricle in sufficient concentration to cause respiratory depression. Another study conducted by Varassi et al to evaluate the ventillatory effects of subarachnoid Fentanyl in the elderly. ${ }^{21}$ They concluded that intrathecal Fentanyl did not alter respiratory rate, end tidal tension of $\mathrm{CO}_{2}$, minute ventilation, respiratory drive, respiratory timing or the ventillatory response to $\mathrm{CO}_{2}$.

\section{Conclusion}

In conclusion, $25 \mu \mathrm{gm}$ Fentanyl appears to be an attractive additive to intrathecal Bupivacaine in elderly patients undergoing cemented bipolar prosthesis under spinal anaesthesia. Good quality of intraoperative analgesia and hemodynamecally stable conditions are obtained with minimal side effect. In this study we have large number of patients, so the study is more genuine than previous study.

\section{Conflict of Interest: None}

\section{References}

1. Michael K Urban. Anesthesia for orthopaedic surgery, Philadelphia. Elsevier. 2015 Miller's Anaesthesia $8^{\text {th }}$ ed. vol:2;2386.

2. Avidan MS, Searleman AC. "Long-term cognitive decline in older subjects was not attributable to noncardiac surgery or major illness". Anesthesiology, 2009;111(5): 964-970.

3. Avidan MS, Evers AS. "Review of clinical evidence for persistent cognitive decline or incident dementia attributable to surgery or general anesthesia". $J$ Alzheimers Dis. 2011;24(2):201-216.

4. Lee HB,kasper JD, Shore AD, Yokley Jl, Black BS. level of cognitive impairement predicts mortality in high risk community samples; J Neuropsychiatry Clin Neurosci. 2006;18:543.

5. Ritchie K, Polge C, de Roquefeuil G, Djakovic $\mathrm{M}$, Ledesert B "Impact of anesthesia on the cognitive functioning of the elderly" Int

Psychogeriatr. 1997;9(3):309-326.

6. Dijkstra JB' ${ }^{1}$, Van Boxtel MP, Houx PJ, Jolles J. “An operation under general anesthesia as a risk factor for age-related cognitive decline: results from a large crosssectional population study" J Am Geriatr Soc. 1998;46(10):1258-1265.

7. Bugg DJ, Power Ck, Meeke R. Prevention of Spinal Anaesthesia induced hypotension in the elderly: i.m. Methoxamine or combined hetastarch and crystalloid. $B R$ J Anaesth. 1998;80:199-200.

8. Favarel-Garrigues JF, Sztark F, Petithean ME. Hemodynamic effects of Spinal Anaesthesia in the elderly: Single dose versus Titration through a catheter. Anaesth Anal. 1996;82:213-216.

9. Critchley LA, Conway F. Hypotension during Subarachnoid Anesthesia: Hemodynamic effects of colloid and metaraminol. Br J Anesth. 1996;76:734-736.

10. Ben-David B, Frankel R, Arzumonov T. Minidose Bupivacaine-fentanyl Spinal anaesthesia for surgical repair of Hip fracture in the aged. Anaesthesiology. 2000;92:6-10.

11. Critchley LA, Yu Sc. A comparative study of three different methods of administering metaraminol during spinal anaesthesia in the elderly. Anaesth Intensive care. 2001;29:141-148.

12. Wang C, Chakrabartim MK, Whitwani JG. Specific enhancement by fentanyl of the effect of intrathecal bupivacaine on nociceptive afferent but not on sympathetic efferent pathways in dogs. Anaesthesiology. 1993;79:766-773.

13. Schubert A, Licina MG, Line bery PJ, Deers MA. The effects of intrathecal morphine on somatosensory evoked potentials in awake humans. Anaesthesiology. 1991;75:401-405.

14. Ben-David B, Solomon E, Levin H. Intrathecal fentanyl with small dose dilute bupivacaine: Better Anaesthesia without prolonging recovery. Anaesth Analg. 1997;85:560-565. 
15. Leos, Sng BL, Lim Y, Sia AT. A randomized comparison of low doses of hyperbaric bupivacaine in combined spinal-epidural anaesthesia for caesarean delivery. Anaesth Analg. 2009;109(5):1600-1605.

16. Roofthooft E, Van de Velde M. Low dose spinal anaesthesia for caesarean section to prevent spinal induced hypotension. Curr Opin Anaestheol. 2008;21(3):259-262.

17. Van de Velde M, Van Schoubroeck D, Jani J, Teunkens A, Missant C, Deprest J. Combine spinal epidural anaesthesia for caesarean section: Dose dependent effects of hyperbaric bupivacaine on maternal hemodynamics. Anesth Analg. 2006;103(1):187-190.

18. Bogra Jaishree, Amora Namita, Srivastava Pratima. Synergistic effect of Fentanyl \& Bupivacaine in spinal anaesthesia for caesarean section. BM Anesthesiol. 2005;5:5

19. Liu S, Chiu A, Carpenter R. Fentanyl prolongs lidocaine spinal anaesthesia without prolonging recovery. Anaesth Analg 1995;80:730-734.
20. Vaghadia H, Mc Leod D, Mitchell G. Small dose hypobaric lidocaine-fentanyl spinal anaesthesia for short duration outpatient laproscopy. A randomized comparision with conventional dose hyperbaric lidocaine. Anesth Analg. 1997;84:59-64.

21. Varassi G, Celleno D, Capogna G. Ventillatory effects of subarachnoid fentanyl in the elderly. Anaesthesia. 1992;47:558-62.

How to cite this article: Gohiya S, Gohiya V K, Singh N. Study of addition of fentanyl to bupivacaine in subarachnoid block administered for cemented bipolar prosthesis in geriatric patients population. Indian J Clin Anaesth. 2018;5(4):501-504. 